\title{
Students' Perception Towards Retail Management Skills Through Managing Business Simulation At Centre Of Retail Excellence (CORE)
}

\author{
Noraini bte Hashim ${ }^{1}$ and Salehan bin Marsim ${ }^{1}$ \\ \{norainihashim@psas.edu.my,salehan@psas.edu.my \} \\ ${ }^{1}$ Polytechnic of Sultan Azlan Shah, Behrang, Perak, Malaysia
}

\begin{abstract}
This study was conducted to identify students' perception towards retail management skills through managing business simulation at Centre Of Retail Excellence (CORE). Sample is a Diploma in Retail Management (DRM) students at Politeknik Sultan Azlan Shah (PSAS), Perak which managed CORE during their study. At Polytechnic Sultan Azlan Shah (PSAS), Centre of Retail Excellence (CORE) is a business simulation for teaching and learning process for DRM students. The sample size was 125 people who were randomly selected and distributed questionnaires through on-line survey. This study involved students of Diploma in Retail Management (DRM) semester 4, 5, 6 and alumni DRM. The objectives of this study was to identify students' perception towards retail management skills by managing CORE and to identify the types of skills gained by students through managing CORE. The study was analysed by using excel in Google Drive. From this study it can be concluded that by giving the students opportunity in managing CORE, there are positive perception in increasing retail skills among students DRM. In addition, it is also concluded that the skills used in managing CORE is a skills needed by employers.
\end{abstract}

Keywords: work, business simulations, retail management, retail skills.

\section{Introduction}

Through a study at the UniversitiKebangsaan Malaysia (UKM), there are seven factors related to unemployment in the country. It is cyclical, structural, technological, seasonal, frictional, volunteers, and intangible. Simulation is the imitation of the real situation. Business simulation method is a method that can be used in teaching and learning process. The basic idea is to build a simulation experiment, or simulator, which will act as a system of interest in certain aspects which are important in an effective way fast and save cost (Gloud, 1993) This method is also more realistic than other learning methods (Faria, 1998).

Technical skills rather obvious task for the simulation has been widely used in construction (Robert, 2009). Crisis simulation rather unique in its effectiveness cannot be measured against other means of training and simulation provides the only way to experience being used to train people in an environment as realistic as possible for unknown crisis (Rolfe, 1992).

The simulation is to learn skills in the system, practical and entertainment. The advantage of simulation is that the system can analyse the best and easy to handle other problems. Tracer studies that have been conducted since 2007 until 2010 for the Diploma in Retail Management showed that $87 \%$ were employed in the retail sector after 6 months of completing the study, $6 \%$ of graduates have become entrepreneurs and $7 \%$ further their study. 


\subsection{Problem Statement}

DRM is the only programme in the Commerce Department at Polytechnic Sultan Azlan Shah (PSAS), which is using simulation concepts in the teaching and learning process since 2012. The business simulation is named as Centre of Excellence Retail (CORE). The use of business simulation is very useful for all students, especially Retail Management students. The third year students will be exposed with all aspect of retail skills and knowledge by managing CORE.

The other courses attended by students in class including human resource management, customer service, retail purchases, retail promotions, buying, dealing with suppliers, visual merchandising and fashion items. This will equip students with relevant knowledge to be more marketable in industry.

Besides, at CORE, students were exposed with the experience of managing the retail outlet. They were also learning about the loyalty, teamwork, team building, honesty, punctuality, and responsibility. These qualities will help students be more qualified and competent in getting a job after graduating.

Through this technique of teaching and learning process which combine conventional class with simulation, students of Diploma in Retail Management will have value added specially on retail knowledge and skills after graduating from Diploma Retail Management. According Ahmad (2008) et al, employers not only need technical skills, but also employability skills from students to be their employees. Since DRM students have chance to do simulation work during their study, they should get the right technical and employability skills before they are graduate. This study focuses on the technical and employability skills learned by students DRM through managing CORE.

\subsection{Research Question}

1) What is the students' perception towards retail management skills by managing CORE?

2) What types of employability skills students gained through managing CORE?

\subsection{Research Objectives}

1) To identify the students' perception towards retail management skills by managing CORE?

2)To identify types of employability skills students gained through managing CORE?

\section{Literature Review}

This research is referring to a study on enhancing student employability through business simulation at Centre of Retail Excellent, PSAS. This study of literature can enhance the understanding of the investigator on theories that relevance on problem scrutinized. Besides, the literature review must provide the context of research by looking what problem that already been overcome in the research.

This chapter discuss on literature review that study earlier retrieval researcher on variable that is existing like student employability, simulation store and Centre of Retail Excellent, (CORE). Literature review or literature survey is study work that ever committed by others.

\subsection{Employability Aspect}

A study conducted by the National Higher Education Research Institute (IPPTN) (2007a; 2007b) found that in general, employers need employees who have the skills to communicate 
with the characteristics of a good personal and knowledgeable in the field of ICT. General skills required by employers are language skills, general knowledge and current, the ability to serve customers, general knowledge in ICT and work experience or exposure. The study found that even graduates feel that they have acquired the skills necessary ICT and language while studying in institutions of higher learning, the lecturer thought otherwise. The lecturers felt that the performance and abilities of their students is slowly declining in terms of communication skills, confidence, thinking and problem solving skills as well as motivation and attendance in college. There are serious problems to demonstrate the readiness of graduates to work. To address this problem, employers have suggested that a period of industry training to graduate lengthened.

A study conducted by the International Employer Barometer (IEB) on graduate employability: It found that $86 \%$ of employers consider good communication skills are very important, and most employers are less satisfied with the way the graduates presented themselves with effective. The study involved a total of 233 respondents representing employers 750000 workers of the total number of employers, $43 \%$ of which are small companies with less than 100 workers, while $27 \%$ of companies with between 100 and 1,000 employees, while $30 \%$ are companies with more than 1,000 employees. In addition, soft skills such as teamwork is very important, even more important than even the core skills of writing and number skills considered important by $70 \%$ of employers. The study also found that $65 \%$ of employers say that professional work experience abroad will make it easier for graduates to find jobs. In terms of recruitment, the use of online media is the most effective method, where $91 \%$ of employers stated that they use this method and $94 \%$ of employers rate it as the best method in the hiring process.

A study on the employability of graduates nowadays it is very important that provide many benefits to higher education institutions in Malaysia and to graduate within itself. Factors affecting jobs is the quality level of education, the readiness of employers to recruit local graduates, the development of the Malaysian economy and the quality of its graduates. Parties also identified eight reassures criteria a major factor for employers where most graduates still fail to meet the communication skills both orally and in writing, the flexibility and mobility, a desire for learning, presentation skills, proactive behaviour, interpersonal skills, the ability to produce ideas and good discipline.

Therefore, the proposed study will look at the factors that are important employability a priority for employers in the hiring process of new employees, their perception of the quality of local graduates who are working with them, had a mismatch in workers among graduates and evaluate the System University local education can produce graduates who meet the needs of employers.

\subsection{Employability}

Employability is a set of achievements the skills, understandings and personal attribute that make graduates more likely to gain employment and be successful in their chosen occupations, which benefits themselves, the workforce, the community and the economy. In addition to employability, the research is made for see the ability, skills and student knowledge after doing work at business simulation.

Employability is not the same as gaining a graduate job, rather it implies something about the capacity of the graduate to function in a job and be able to move between jobs. Therefore concerned with exploring whether and how the effective in gaining employability skills and attributes. 
Based on Rae (2007), the part of achieving a high level of performance in employability is ensuring leaner engagement. This is because, to determine focus of research the practical and knowledge of the business simulation for increase the student employability. According Robert (2009), having the knowledge that the quality of their work would directly affect the work and success of others seemed to make students feel responsible when doing the work.

Based on Harvey (2001), the quality of employability in an institution is most effectively measured by the quality of the employability development opportunities which a given offers to student. This research reveals the effects which this form of learning had on student employability both through affording opportunities for students to gain transferable skills but also through implementing an integrated approach to delivering employability by Rae (2007).

After that, according Forrier (2003), the main aim of employability is it was still to achieve full employment, but as a result of increasing unemployment attention shifted from factors relating to attitude towards aspects of knowledge and skills. Employability means of achieving flexibility within organization and the functional flexibility of staff (Forrier, 2003). Furthermore, a considerate amount of employability research studies the employability of specific group such as unemployed, students or employees. Moreover, we can see from employability activities that using to enhance the movement capital by providing new knowledge and skills. The employability examines activities that enhance student such as training, job rotation and career guidance.

Besides, from Robert (2009), we get learning transferability and articulating skills. The research evidence to illustrate that in realistic work related activity such as negotiating contracts and price and having to deal with complexities in communication for student. From the journal, we can know the effects of employer feedback on student. The value of these experiences, both in enhanced reflection and confidence is acknowledged in research which places a self-efficacy as the learner employability (Yorke, 2006).

Based on Archer (2008), the aspect of enhancing student employability is very important because as employers place honesty high on their list of desirable employability characteristics of a graduate. According to Rae (2007), where students see the value of their work, their engagement would improve as well which responds to some fears of lack of engagement with employability content.

\subsection{Business Simulation}

The simulation is a PC-based simulation that gives the student experience in developing and implementing strategies (Declan 2010). Besides, simulation also give the student an experienced in developing strategies, decision making, team building and marketing skills. The attempt was made to simulate realistic competitive conditions as much as possible so that the concept learned and solutions generated could be transferred from the classroom to the outside business environment. An interactive environment provide by simulation exercise in which participants are enabled to learn through practice, discourse, communication and social interaction. The skills and competencies that are increase can be achieved through the mastery of rules and their selective application. However, the specific nature of crises not only requires rules and procedures to be applied flexibly and creatively, but they often need to be adjusted or new ones need inventing, which offers opportunities for learning at higher cognitive levels (Edward 2002).

Besides, from a UK survey (Fripp, 1993), simulations reported by the users that it is stimulating and enjoyable, a clear prerequisite of learning. Frequently, for the development of team working skills and demonstration, the simulation was a valuable basis. Not only that, simulation also can offer a risk-free environment at both individual and organizational level. 
Next, simulation can also provide a quick and unmistakable feedback and it will allow people to see the consequences of their decision.

They said to consider the effectiveness of simulator devices for achieving their purpose, the simulation must be pragmatic (Edward 2002). On the other hand, state that learning in simulation activity occurs on many levels. The learners learn from the contextual information that contained in the dynamics of the activities, the process of the activity that is resulting from the decision making. (Declan 2000).

\subsection{Relationship Between Business Simulation And Employability}

Wolfe and Roberts (2009) that it is valid representative the simulation is the real-world issues facing managers and that the environment offered by simulations can be among the most realistic offered in off-the job training. With the existing of business simulation, it is true that it was stimulating and enjoyable and a very clear of learning. Business simulation is directly can help the students to increasing their knowledge and also can gain an experience during their studies. People don't learn from actual experiences, instead they learn from reflecting on the experience. Debriefing helps participants to reflect on their simulation experience and to learn transferable skills and concepts, (Thiagarajan, 1994).

According to Faria (1989), they concluded that simulation is effective in improving quantitative skills but not improving the acquisition of applied or theoretical knowledge. This is because skills that student have can help them in industry world. Besides, student can help the company with their skill and knowledge. It is very important.

\subsection{Backgroud Of Business Simulation Room (Core)}

CentreofRetailExcellence(CORE) is aone-stop centrethat combining ofteaching and learning process, life-long learning,practical training forstudents of Diplomain Retail Management(DRM) as well asa one-stopadvisory serviceretailing. The centre has beendevelopedby Head of Program Diplomain Retail Management(DRM) on 2013, Mrs.NorainibteHashimwith7lecturersof DRM. With the supportofthe Head of Departmentat the time,Ms.HajjahNorhayatiMohamedNor. COREisfully managed byDRMstudentsandeventuallygrowing the spaces in collaboration withPSASEntrepreneurshipUnit. 


\subsection{Theoretical Framework}

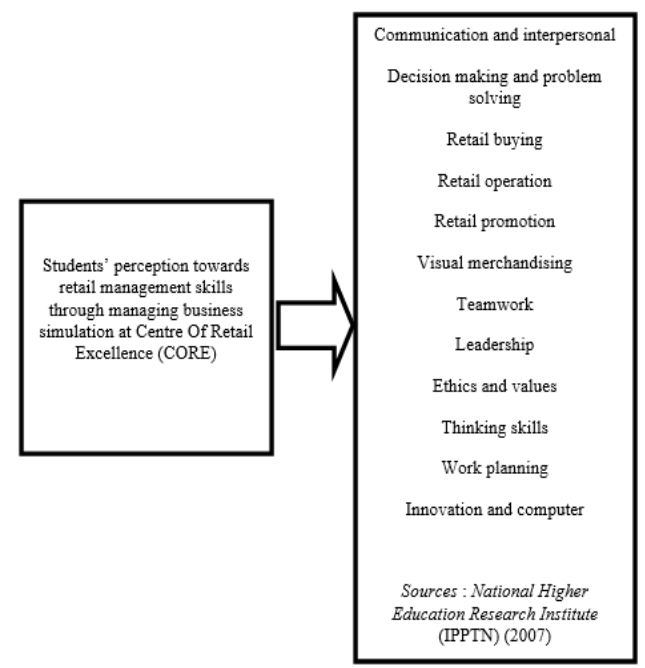

Fig.1. Theoretical Framework

\section{Research Methodology}

In this chapter, we discuss about the six methodologies that we use to complete our research. The six methodologies include research design, research population, research sample, research instrument, data collection procedure, data analysis and research location.

\subsection{Research Approach}

We have chosen quantitative as a method for research approach. The questionnaire used in the survey is adapted by the journal (Ismail, 2012) and student semester 4, 5, 6 and former Diploma in Retail Management (DRM) start session December 2013 were the respondents. The aim for our study is to identify "Students' perception towards retail management skills through managing business simulation at Centre Of Retail Excellence (CORE)."

\subsection{Research Population}

Population of our respondent for this study is 184 respondents. It is during total from first batch student DRM handle the CORE. It include student DRM semester 4, 5, 6 and alumni.

\subsection{Research Sample}

Population for this research is Alumni DRM which had experienced managing CORE, DRM5 and DRM6 which is 184 students. According Krejcie and Morgan (1970) sample for this number of population is 120 respondents. The sampling technique used is simple random sampling.

\subsection{Research Instruments}

Through the questionnaire that we have, it have 2 section which is $\mathrm{A}$ and $\mathrm{B}$. Questionnaire has two parts as follows: 
I. Section A - Respondent demographics.

II. Section B - Semester 4, 5, 6 and former DRM's perception about student employability thorough business simulation.

Questionnaire is adapted from a research "Study on Employability of Graduates in Malaysia: A Survey of Employer Perspectives” (Ismail, 2012).

\subsection{Data Collection Procedure}

Data collection procedure we do is through the online questionnaire. So all the respondents need to answer all the questions. Form that we can get the answer and make conclusion.

\subsection{Data Analysis}

Data from various sources are collected, reviewed, and then analysed to form a conclusion. There are specific methods of data analysis, organizing, interpreting and summarizing data. Data analysis techniques related to how the study will perform troubleshooting procedures to answer the research problem. In compiling the research method or methodology, data analysis technique described and explained in absolutely clear and detailed.

This study are quantitatively technique, then it must be defined the stages through which it passes is clearly quantitative. In data analysis technique have also elaborated on how the technique for testing or obtaining a valid data reliable. We have used frequency as our method the clear result. The data obtained in the study will be analysed using drive Google.

We have five classification based on questionnaire. It included the scale from 1 until 5. Besides, it shows what respondent choose for the questionnaire. We have use a Likert scale for this questionnaire.

$$
\begin{aligned}
& 1=\text { Strongly Disagree } \\
& 2=\text { Disagree } \\
& 3=\text { Medium } \\
& 4=\text { Agree } \\
& 5=\text { Strongly Agree }
\end{aligned}
$$

Otherwise, from the 5 classification it can separate to three categories of impact. It is positive impact, medium impact and negative impact. According Wiersma, W. (1995) score mean is classified as:

\begin{tabular}{|l|l|}
\hline Mean Score & Interpretation \\
\hline $1.00-2.3$ & Low/Negative Impact \\
\hline $2.4-3.7$ & Medium \\
\hline $3.8-5.00$ & High/positive impact \\
\hline
\end{tabular}

Sources: Wiersma W.(1995) 


\section{Findings}

From this research, it found that students' perception towards retail management skill is as follow:

Table 1. Mean for skills enhancing in managing CORE

\begin{tabular}{|c|c|c|c|c|c|c|}
\hline No & Skill & 1 & 2 & 3 & 4 & 5 \\
\hline 1 & Communication and Interpersonal & 0.2 & 0.2 & 1.9 & 4.2 & 3.7 \\
\hline 2 & Decision Making and Problem Solving & 0.3 & 0.1 & 1.4 & 4.9 & 3.1 \\
\hline 3 & Retail Buying & 0.1 & 0.3 & 0.7 & 3.4 & 3.1 \\
\hline 4 & Retail Operation & 0.2 & 0.2 & 0.7 & 3.1 & 3.5 \\
\hline 5 & Reatail Promotion & 0.2 & 0.1 & 1.2 & 3.1 & 2.8 \\
\hline 6 & Visual Merchandising & 0.2 & 0.3 & 0.1 & 2.8 & 3.3 \\
\hline 7 & Leadership & 0.2 & 0.3 & 0.1 & 4.5 & 4.2 \\
\hline 8 & Teamwork & 3.3 & 0.2 & 0.8 & 4.8 & 2.3 \\
\hline 9 & Work Planning & 0.3 & 0.4 & 1.3 & 4.7 & 3.3 \\
\hline 10 & Thinking Skill & 0.2 & 0.1 & 1.5 & 4.8 & 3.5 \\
\hline 11 & Ethics and Value & 0.3 & 0.2 & 1.2 & 4.7 & 3.8 \\
\hline 12 & Computer & 0.2 & 0.2 & 1.9 & 4.5 & 3.5 \\
\hline
\end{tabular}

From Table 1, it shows that by managing CORE, students perceive that they can enhance all skills needed in handling retail outlet. It means that they get real knowledge by practicing retail knowledge in the simulation mart. It shows that 4 skills is in medium which are retail buying, retail operation, retail promotion and visual merchandising. While others skills and qualities have positive impact to the students. It can be concluded that, students are enhancing their skills and qualities of employability through managing CORE.

From this study, it founds that there are 12 skills and qualities applied at CORE is relevance to retail management and students agree that they have gained this skills through managing CORE. The skills are:
a. Communication and interpersonal
b. Decision making and problem solving
c. Retail buying
d. Retail operation
e. Retail promotion
f. Visual merchandising
g. Leadership 


\section{h. Team work \\ i. Work planning \\ j. Thinking skills \\ k. Ethic and values \\ 1. Innovation and computer}

From this study, we found that by managing CORE, there is an enhancement retail skills among students DRM. Most respondents agreed that the skills they acquired during the activities done at CORE can increase the quality of work. The activities that student do in business simulation such as good communication skills both written and verbal, another alternative to consider before making a decision, can give direction clearly and fluent, have a confident in communicate information, can deliver opinion that convinces others, consider a valid of information before making a decision, to make anticipate potential problems in the future, responsible for the action and decision, can fine information service through the internet, proficient with word processing such as post system, analytically thinking, and the last one is innovation and computer. Besides this research, all of this skills are tested practically by lecturers and being graded. They must pass the skills as a graduation requisite for Diploma in Retail Management students.

\section{Conclusion}

It also can be concluded that there are skills that are needed by employer which is lead to higher rate of employability. The results of this study found that the same skills as the research conducted by the National Higher Education Research Institute (IPPTN) (2007). Employer need employee who have the skills to communicate with the characteristics of a good personal and knowledgeable in the field of ICT. Besides, language skills, general knowledge and current, the ability to serve customers, general knowledge in ICT and work experience or exposure, slowly declining in terms of communication skills, confidence, thinking and problem solving skill (National Higher Education Research Institute (IPPTN) (2007). The others skills can get from the CORE is retail buying, retail operation, retail promotion, visual merchandise, leadership, teamwork and work planning.

\section{Recommendations}

Based on the findings and conclusion of the study, here are recommendation to be considered: Recommendation for leadership:

a. Give a motivate to teamwork

b. Support each other

c. Distribute work based on their strength

d. Have to unsure subordinates follow the guideline to achieve the goals

e. Show a good example to subordinates

Recommendation for teamwork:
a. Contribute expertise on teamwork
b. Give a good suggestion
c. No more repression
d. No more factionalism
e. Establish a good cooperation 


\section{References}

[1] Archer, and Davison,J. (2008) Graduate Employability: The views of employers, The Council for Industry and Higher Education, London

[2] Declan Doyle and F. William Brown (2000), Using A Business Simulation To Teach Applied Skills- The Benefits And The Challenges Of Using Student Teams From Multiple Countries.

[3] Edward Borodzicz and Kees van Haperen (2002), Individual and Group Learning in Crisis Simulation.

[4] Faria, A. J., \& Whitely, T R(1989). An Empirical Evaluation Of The Pedagogical Value Of Playing A Simulation Game In A Principles Of Marketing Course. Development In Business Simulation And Experiential Learning, Issue 17, pp53-57

[5] Faria, A.J. (1998), "Business Simulation: Current Usage Levels - An Update", Simulation And Gaming, Vol. 29, pp. 295-308

[6] Gould Floyd Jerome, G. D. E. C. P. S., (1993).Introductory Management Science. 4 ed. s.l.:Prentice Hall.

[7] Forrier and Little Sels (2003) Vocational Higher Education - Does it meet Employers' need? Learning and Skills development Agency, London.

[8] Fripp,J. 1993, Learning through Simulations, McGraw Hill,London.

[9] Gosenpud, J., \&Washbush, J (1993). Comparing the simulation with the case approach: using criteria appropriate for the simulation. Developments in Business Simulation \& Experiential Exercise, 20,126.

[10] Harvey, L. (2001) 'Defining and measuring employability', Quality in Higher Education, Vol. 7, No. 2, pp. 97-109.

[11] Ismail, M. H. (2012). Study on Employability of Graduates in Malaysia: A Survey of Employer Perspectives. Prosiding Persidangan Kebangsaan Ekonomi Malaysia Ke VII (pp. 906-913). PERKEM V.

[12] InstitutPenyelidikanPendidikanTinggi Negara (IPPTN), 2007.KajianMasalahPengangguran Di kalanganSiswazah. KementerianPengajianTinggi.PelanStrategikPengajianTinggi Negara: PeletakanAsasMelangkaui 2020, 2007.

[13] Krejcie, Robert V., Morgan "Determining Sample

[14] Size for Research Activities”, Educational and Psychological Measurement (1970)

[15] Rae, D. (2007), "Connection enterprise and graduate employability: challenges to the higher education culture and curriculum", Education\&Training

[16] Robert E. Wood (2009), "Simulation, learning and real word capabilities", Education \& Training.

[17] Rolfe, J.M (1992) 'Training Transfer. The Basic For Validating Effectiveness' Simulation Games For Learning, Issue 22(vol4).pp 249-259

[18] Sanger, Spiker, D., Williams, \& N., B. (2007). Opinion Of Female Juvenile Delinquents On Communication, Learning and Violence. Journal Of Correctional Education, pp 69-92.

[19] Thiagarajan, S (1994) 'How I designed a game -and discovered the meaning of life', Simulation and Gaming 25:529-535

[20] Utusan Online (2011) Pengangguran di Malaysia Antara Paling Rendah

[21] Van der Heijden, B (1999) 'The relationship between job- related factors and the development of professional expertise throughout the career', Conference Human Resource Management: confronting Theory and Reality, Rotterdam 
[22] Washbush, J., \&Gosenpud, J. (1993) The relationship between total enterprise simulation performance and learning. Developments in Business Simulation \& Experiential Exercises, 20,141

[23] Wiersma, W. (1995). Research methods in education: An introduction. Boston: Allyn\& Bacon.

[24] Yorke, M. and Knight, P. (2004), "Self -theories: some implications for teaching and learning in higher education", Studies in Higher Education. 